\title{
Knowledge Management and Problem Solving in Real Time: The Role of Swarm Intelligence
}

\author{
Chris William Callaghan \\ School of Economic and Business Sciences, \\ University of the Witwatersrand, Johannesburg, South Africa
}

\section{Chris.Callaghan@wits.ac.za}

\begin{abstract}
Knowledge management research applied to the development of real-time research capability, or capability to solve societal problems in hours and days instead of years and decades, is perhaps increasingly important, given persistent global problems such as the Zika virus and rapidly developing antibiotic resistance. Drawing on swarm intelligence theory, this paper presents an approach to real-time research problem-solving in the form of a framework for understanding the complexity of real-time research and the challenges associated with maximizing collaboration. The objective of this research is to make explicit certain theoretical, methodological, and practical implications deriving from new literature on emerging technologies and new forms of problem solving and to offer a model of real-time problem solving based on a synthesis of the literature. Drawing from ant colony, bee colony, and particle swarm optimization, as well as other population-based metaheuristics, swarm intelligence principles are derived in support of improved effectiveness and efficiency for multidisciplinary human swarm problem-solving. This synthesis seeks to offer useful insights into the research process, by offering a perspective of what maximized collaboration, as a system, implies for real-time problem solving.
\end{abstract}

Keywords: Knowledge management, crowdsourcing, swarm solving, theory development, complex problem solving

\section{Introduction}

The application of knowledge management theory to management in different fields can make an important contribution. One example of such application is in the processes underlying the innovative development of new pharmaceuticals and drugs essential to human health outcomes. Recent advances in medicine, such as the emergence of biologics, or protein-based drugs, including gene-based (gene-therapy) biologics, offer new hope where no other treatments have been previously available (FDA, 2015). Similarly, the outcomes of innovative research, such as the recent

Material published as part of this publication, either online or in print, is copyrighted by the Informing Science Institute. Permission to make digital or paper copy of part or all of these works for personal or classroom use is granted without fee provided that copies are not made or distributed for profit or commercial advantage AND that copies 1) bear this notice in full and 2) give the full citation on the first page. It is permissible to abstract these works so long as credit is given. To copy in all other cases or to republish or to post on a server or to redistribute to lists requires specific permission and payment of a fee. Contact Publisher@InformingScience.org to request redistribution permission. discovery of a new antibiotic without detectable bacterial resistance, namely, teixobactin (Ling et al., 2015), offer new hope in the face of the rise of 'superbugs' like methicillin-resistant staphylococcus aureus (MRSA) (Northeastern University, 2015) or others recently found to be resistant to last-line drug colistin (Pierson \& Berkrot, 2016). At the heart of this scientific progress, 
however, is the application of knowledge management theory, which relates research processes and the management of knowledge and information to knowledge creation. Knowledge problems related to constraints to innovative scientific production require knowledge management theory development for scientific progress to occur.

Arguably, a knowledge problem exists, which is reflected in constrained pharmaceutical innovation (Grasela \& Slusser, 2014; E. C. Hayden, 2014; F. Hayden, 2006; Munos, 2009). With the global innovation pipeline providing new innovations and pharmaceutical drug development having been 'nearly broken' (McKenna, 2014), human populations may increasingly be under threat. Staying with the example of health disasters, emergent threats exist in the form of Ebola (Krishnan, 2014), antibiotic resistance (Halifax, 2013) and disease re-emergence in the form of polio in Nigeria (Ajumobi, 2014) and Pakistan (Zia, 2014), for example. Although recent successful innovation outputs such as biologics (FDA, 2015) and resistance-free antibiotics (Ling et al., 2015) may offer limited evidence against arguments that the pharmaceutical innovation pipeline is 'nearly broken' (McKenna, 2014), this paper argues that this pipeline exists under structural 'bottleneck' conditions which are associated with the knowledge aggregation problem, making it unable to increase innovation dramatically, but that techno-centric knowledge management theory premised on maximizing knowledge sharing, which is synthesized from swarm intelligence literatures, can offer new opportunities for innovations via the more effective harnessing of collective intelligence.

Swarm intelligence relates to the collective behavior of decentralized, self-organized systems, either as found in nature or applied to solving problems in science (Kennedy, Eberhart, \& Shi, 2001). The contribution of this paper is the identification of a source of theory around collective intelligence (Malone \& Klein, 2007; Malone, Laubacher, \& Johns, 2011; Surowiecki, 2004; A. W. Woolley, Chabris, Pentland, Hashmi, \& Malone, 2010) in terms of how knowledge is managed in nature, for example, by social insects (Farmer, Packard, \& Perelson, 1986; Krishnanand \& Ghose, 2005; Storn \& Price, 1997; Yang, 2010), or of how certain theory derived from the field of swarm intelligence (Bonabeau \& Théraulaz, 2000), as well as the theory of markets (Fama, 1970, 1995; A. Smith, 1776/2003), can be applied in the area of knowledge management to improve 'real-time' problem-solving capability.

Drawing from theory relating to swarm intelligence and other aspects of collective intelligence, an approach to real-time research problem solving is presented, namely, human swarm solving, offering a framework for understanding the implications of maximizing collaborations in support of urgent and important scientific problem solving. By offering a re-conceptualization of realtime research problem solving, human swarm solving as a method, in turn, offers a useful heuristic exercise in modeling what maximized collaboration in scientific problem solving may look like, offering theoretical, methodological and practical implications that are potentially useful for those across fields seeking to understand the effectiveness and efficiency of research systems.

The objectives of this paper are to derive explicit theoretical, methodological, and practical implications from swarm intelligence literature, to focus scholarly attention on the knowledge aggregation problem and its consequences for innovation, and to offer a model of human swarm solving, in support of real-time problem solving which addresses the challenges associated with the knowledge aggregation problem.

The paper proceeds as follows. First, examples are used to highlight the knowledge problem that this paper seeks to address and to justify the importance of this research. The consequences of lack of knowledge on how to respond in real time to such problems are considered, and the contribution of this paper to the literature is justified using this rationale. Next, swarm intelligence theory is considered, and principles are derived that are common to forms of crowd-based problem solving relevant to real-time crowd-based, or crowdsourced, research and development 
(R\&D). Theory relating to collective intelligence is then reviewed, providing understandings of theoretical frameworks, with a particular focus on crowd-based price problem solving in markets. What then follows is a discussion that develops the concept of engagement of the 'horizontal' interface of the crowd with a problem space (drawing from swarm intelligence theory), or stigmergy, as well as the 'vertical' interface of the crowd, or elements of coordination by the crowd (drawing from theory related to how crowds coordinate activities). Finally, ant colony systems, particle swarm optimization, and honey bee algorithms are considered as examples of mechanisms offering workable insights into how principles drawn from the swarm intelligence literature can be applied to human swarm solving. The knowledge problem addressed in this paper is now introduced.

\section{Knowledge Problem}

A central argument of this paper is that knowledge management has an important role to play in solving certain societal problems and that an urgent response is needed to address the potential of global threats that require a research response in real time or that can solve global problems in a matter of hours or days, rather than months or years. The knowledge problem addressed in this research is (i) the absence of a dedicated body of theory, or a field of literature, that explicitly draws together theory and practice in support of attaining real-time research capability, and (ii) the absence of theory effectively harnessing collective intelligence as a solution to the knowledge aggregation problem. At the heart of the knowledge aggregation problem is stickiness of information (Von Hippel, 1994) or the difficulties inherent in bringing tacit knowledge together quickly across time and geographical distance to solve problems in immediate time. The knowledge aggregation problem was originally identified by Hayek (1945).

Evidence to date of the efficacy of the probabilistic innovation approach to make inroads into addressing the knowledge aggregation problem exists in the successes of open innovation platforms and high volume data collection, synthesis and analysis capabilities provided by recent technological advances which have made crowdsourcing and social media data management possible. 'Proof of concept' of the use of the crowd to solve scientific problems is evidenced in the success of crowdsourcing platforms such as Innocentive (Allio, 2004; Howe, 2006), effective crowdsourcing use for task completion across different work contexts (Chan \& Holosko, 2015; Malone et al., 2011), crowdsourcing for social innovation (De Falco, Vargas-Sánchez, \& Cucari, 2015) and other collaborative data collection and analysis platforms (J. Woolley, Madsen, \& Sarangee, 2015). Crowdsourced research and development (R\&D), or crowdsourcing applied to analysis as well as data collection, has also demonstrated success when applied to disaster management (Aye, Sprague, Cortez, Prenger-Berninghoff, Jaboyedoff, \& Derron, 2016; Davies, 2015), medical research, and health informatics (Torr-Brown, 2013). The probabilistic potential of crowdsourcing and social media use for large data collection, synthesis, and analysis is particularly useful in real-time disaster contexts where problem-solving processes rely on complex adaptive systems (Coetzee, Van Niekerk, \& Raju, 2016). A body of literature with an explicit focus on bringing together theory on swarm and collective intelligence in support of real-time problem solving might, therefore, be helpful to focus theory development on fostering real-time problemsolving capability. However, absent from the literature to date has been an authoritative body of theory which effectively predicts how research can respond effectively in real time to solve serious societal problems. It is this gap in the literature that the paper seeks to address. Through this modest contribution, it is hoped that future research will build further on these ideas and that realtime research will ultimately become a reality. Arguably, this research makes the following contributions to the literature.

First, a host of different fields rely on management and knowledge management theory to enable real-time problem solving. In the specific case of the medical field's need for the management of 
real-time problems, in the absence of literature on how to enable real-time research more effectively, the consequences of this deficiency are currently numbered in the lives lost daily to antibiotic resistance (Halifax, 2013) and other microbial threats, and the ever-present danger of airborne outbreaks (Senthilingam, 2015) or other health challenges which will need real-time research responses because in many cases the data needed to solve such a problem will only be available as the problem emerges, termed for our purposes a 'real-time' problem space. The consequences of not making the arguments in this paper might also bear this cost.

Second, such research might help to disseminate ideas and to enable the transmission of ideas across different fields and, therefore, add to the transdisciplinary exchange of theory and best practice, which is particularly salient in problem-solving spaces that have a disproportionate impact on stakeholders. Arguably, the problem of fatal microbial outbreaks is a typical example of such a problem space, and there is little time to lose in developing the conversation offered by this paper.

Third, such research highlights the contribution of new techno-centric knowledge management theory and practice, and therefore management theory, to other fields. The dangers of 'silos' or disciplinary firewalls that maintain separations of fields might be particularly hazardous when these behaviors run counter to the fundamental nature of the process of solving societal problems. It is argued here that under certain conditions (such as those associated with fatal global microbial outbreaks) the nature of problem solving necessarily draws from multiple perspectives. This research also provides a timely synthesis of social media (Alexander, 2014; Yates \& Paquette, 2011) and crowdsourcing (Tierney, 2014) disaster management theory (representing the 'front line' of engagement with real-time problem solving) enabled by recent technological advances, with a body of swarm intelligence theory (Blum \& Roli, 2003; Kennedy, 1999; Storn \& Price, 1997; Yang, 2010; Yesodha \& Amudha, 2012) applying probabilistic mechanisms (Callaghan, 2014a) and metaheuristics useful for harnessing the collective intelligence of large numbers of human problem solvers, or the human swarm (Rosenberg, 2015).

Lastly, it is argued that probabilistic innovation (Callaghan, 2015), or the way exponential increases in the inputs to problems may lead to exponential increases in problem-solving outputs, is a paradigm in knowledge management that is supported by a growing theoretical literature as well as increasing evidence of its efficacy. Probabilistic innovation's epistemological and ontological principles relate to citizen science (Bonney et al., 2009), participant-led research (Steuli \& Vayena, 2016; Vayena \& Tasioulas, 2013) and post-normal science (Funtowicz \& Ravetz, 1994) premised on maximized transparency, engagement, and derived inputs of populations (citizens) in scientific research processes, including in the ethical scrutiny of science. Users (Nielsen, Reisch, \& Thøgersen, 2014) of products of science and innovation outputs, as citizens (Garbarino \& Mason, 2016), are at the heart of an increasing engagement of stakeholder populations, or the crowd, with science, as technology-enabled processes like crowdsourcing and social media usage provide hitherto unrealized potential for connectivity, which makes a synthesis of swarm intelligence literature an important complement to the probabilistic innovation literature.

Probabilistic innovation also recognizes the centrality of emergent properties of self-organizing systems (Forrest, 1990; Johnson, 1998; Kochugovindan \& Vriend, 1998) in maximizing collaborative engagement to attain real-time research problem-solving capabilities and, hence, also the potential for further useful insights drawn from swarm intelligence, as problem solving in real time is uniquely suited to probabilistic mechanisms derived from the principles of swarm intelligence algorithms.

The objectives of this paper are therefore to (i) derive explicit theoretical, methodological, and practical implications from new literature on collective intelligence, swarm solving, and probabilistic innovation, (ii) focus scholarly attention on the consequences of innovation failure, and the 
centrality of the knowledge aggregation problem to this challenge, (iii) provide a synthesis of swarm intelligence, crowdsourcing-related workflow, collective intelligence, and other literatures under the umbrella term 'swarm solving', thus reflecting how social media and crowdsourcing, as emerging technologies, have exponentially increased connectivity and the potential for radically enhanced collaborative problem solving in real time, and (iv) identify enabling conditions supportive of 'swarm solving' in support of radically enhanced data collection, synthesis, and analysis for real-time research problem solving.

These objectives form the basis for developing a model of the socio-technical system and emergent problem-solving processes at the 'coalface' of large-scale problem solving. This model seeks to harness high volume data input, coordination, and analysis in support of real-time problem solving. The overarching objective of this paper was, therefore, to derive principles useful to those seeking to improve the effectiveness and efficiency of research processes across fields, through an analysis of the extreme case of swarm solving, or solving problems in real time, using very large numbers of problem-solving inputs. To attain these objectives, the methodological process followed in this research is conceptual, using analogies to provide a theoretical synthesis of literatures, and to provide plausible examples of how swarm intelligence can usefully be applied to real-time disaster problem solving. At this nexus, swarm intelligence and collective intelligence, and their emerging theoretical bodies of literature, are now considered.

\section{Swarm Intelligence as Collective Intelligence}

The use of the human crowd to solve problems has certain characteristics in common with other social systems and how they solve different problems. An important contribution to the research problem-solving literature is theory relating to swarm intelligence. Swarm intelligence is collective behaviour that emerges from groups of social organisms; an example of swarm intelligence is the way ants solve difficult problems such as finding shortest paths (amongst countless choices) to food in a highly organized way, a form of self-organizing cooperation (Bonabeau \& Théraulaz, 2000).

Swarm solving is taken to be a method of problem solving under conditions of maximized time constraints, where solving a problem effectively reduces the need to increase the probability of finding ideas and knowledge inputs capable of solving the problem; these knowledge inputs can be obtained only by increasing collaborations maximally in real time. However, optimality thresholds at which the disadvantages of congestion overtake the benefits of higher volumes of inputs may typically occur too early in the research process to make swarm solving effective. Nevertheless, through the development of theory it might be possible to derive useful insights into how this 'optimality threshold' might be increased. If it were ultimately possible to manage larger volumes (maximized inputs) of problem-solving inputs effectively, according to probabilistic innovation theory this would increase the probability of solving real-time knowledge problems associated with a crisis, or serious problems, under severe time constraints. Swarm solving can therefore derive useful insights from research into swarm intelligence.

Changes by an insect to the configuration of a nest while building a structure, for example, will trigger other specific actions (in the absence of centralized direction), leading to "an almost perfect coordination of the collective work", a process termed 'stigmergy' (Garnier, Gautrais, \& Theraulaz, 2007, p. 7). This, as a form of collective intelligence, offers certain insights into how human problem solving can be 'leveraged', or obtain returns to scale, when large numbers of individuals participate in problem solving. This is but one example of insights offered by swarm intelligence theory.

This swarm intelligence literature has been the basis for innovations applying principles derived from swarm behaviors, such as overcoming size constraints to hardware miniaturization by using 
large numbers of units that collaborate, such as miniature robots (Bonabeau \& Théraulaz, 2000). Another example is the way mounds akin to "biological skyscrapers result from the work of millions of tiny (1-2 mm long) and completely blind individuals", including complex internal structures allowing for the flow of air and "a succession of chambers connected together with helical ramps ... [which] arise from the twisting and soldering of successive floors" (Garnier et al., 2007, p. 4).

'Pheromone logic', or the way ants find their way by laying down chemical trails, has been applied to robot behavior design, as have other principles, such as those of swarm-bots (s-bots), or robots that mimic the way weaver ants cling together to form larger structures (Bonabeau \& Théraulaz, 2000). Similarly, analysis of banking data has been modeled on the way ants cluster and categorize what they pick up and sort (Bonabeau \& Théraulaz, 2000). The solution to colony problems, for ants, is a collective one; insights drawn from swarm intelligence have in the field of artificial systems led to, for example, discrete optimization, graph partitioning, task allocation, object clustering and sorting, and collective decision making (Garnier et al., 2007, p.4).

Given that swarm intelligence relates to the collective behavior of decentralized, self-organized systems, either as found in nature or applied to solving problems in science (Kennedy et al., 2001), the probabilistic innovation stream of research seeks to build on work considering relationships between mental states, culture, and a social-psychological view of intelligence emerging from culture, which in turn originates in social interaction (Kennedy, 1999). Key to incorporating swarm intelligence theory into this steam of research is knowledge of swarm theory such as particle swarm optimization (PSO), which relates to the development of algorithms to solve problems where solutions represent a point or a surface in n-dimensional space (Kennedy et al., 2001), as well as a host of other work classified as 'nature-inspired' or 'bio-inspired'.

Causal mechanisms and channel principles related to problem solving in natural or biological contexts of swarm intelligence can arguably be applied to human swarm solving, or human swarming in social swarms (Rosenberg, 2015). As is seen in the heuristic case of disasters, where data needed for solving and management are available only after they unfold, theory development related to large-scale data collection, synthesis, and analysis undertaken by human actors can usefully draw on swarm intelligence theory derived from natural or biological contexts. PSO is an example of how optimization can be achieved with high numbers of interactions. This might offer useful insight into how to manage very high volumes of inputs into real-time problem solving, such as that associated with expert crowdsourcing, or managing high volume information inputs in the wake of a crisis or disaster.

Optimization problems typically relate to choices of 'best' configurations of sets of variables to achieve outcomes, and metaheuristics can offer strategies to guide this process (Blum \& Roli, 2003). For nature-inspired algorithms like genetic (Dorigo, 1993) and ant algorithms (Dorigo \& Gambardella, 1997; Dorigo, Maniezzo, \& Colorni, 1996), applying swarm intelligence successfully solved optimization problems (Blum \& Roli, 2003; Dorigo, Birattari, Blum, Clerc, Stützle, \& Winfield, 2008).

Population-based metaheuristics work on a population and perform search processes describing the evolution of sets of points in the search space at the same time; unlike single point search processes or trajectory methods which describe a single trajectory of problem solving in the search space (Blum \& Roli, 2003). Metaheuristics are also differentiated by memory usage; memory-less algorithms typically apply a Markov process using information to determine next action processes drawn from the current state, as memory is a fundamental element of a powerful metaheuristic (Blum \& Roli, 2003). Probabilistic innovation, with its focus on developing theory explicitly related to real-time problem solving in contexts where data required to solve these problems is typically available only after problems unfold, requires the development of such 'memory' quickly 
under initial conditions of zero-memory. These characteristics make the metaheuristics literature an important potential contributor to probabilistic innovation theory.

Bio-inspired methods are increasingly being used successfully in computer networks, security, robotics, biomedical engineering, control systems, parallel processing, data mining, power systems, electronics and mechanical engineering, chemical engineering, production engineering, and molecular biology (Yesodha \& Amudha, 2012). Bio-inspired methods have also been successfully applied to different combinatorial optimization problems, including the assignment problem, knapsack problem, and scheduling problems (Yesodha \& Amudha, 2012).

Computer science and operations research apply ant colony algorithms (Bianchi, Dorigo, Gambardella, \& Gutjahr, 2009; Dorigo et al., 2008; Dorigo \& Gambardella, 1997; Dorigo et al., 1996) as probabilistic problem-solving methods, with applications, for example, in pathfinding, and this method is particularly useful under conditions of imperfect information and limited computational availability. Metaheuristics such as these address situations where solution sets are simply too vast for sampling. Ant colony algorithms have modeled the way ants optimize paths between their colonies and different food sources, laying down pheromone scents which evaporate slowly, indicating recent and more travelled paths, which allow identification of shortest routes to sources (Dorigo et al., 1996). A host of other methods have also been developed from this body of work. Table 1 offers a summary of certain seminal, or 'source' literatures of swarm solving theory, or initial swarm intelligence theory other work has developed from.

In terms of particle theory, or PSO, particles begin with an initial velocity and possess communication properties, as well as fitness criteria, which typically determine acceleration toward problem solving, overcoming challenges associated with local minima (Kennedy et al., 2001). It is possible that principles derived from this research stream can be used to model the interactions of expert crowdsourcing collaborators, for example, modeling of disaster information inputs, the fitness properties of potential contributions and the location of these contributions in relation to collaboration potential.

The metaheuristic artificial bee colony algorithm (Karaboga, 2005; Karaboga \& Akay, 2009) simulates the way bees search for flowers using three states, namely, employed bee, onlooker bee, and scout bee, whereby the first two states relate to local searches closer to solutions chosen by deterministic selection (in the employed bee state) and probabilistic selection (in the onlooker bee state) and the latter (the scout bee) to new opportunities. This model offers advantages associated with a balance between exploration and exploitation, and might usefully be applied to expert crowdsourced R\&D.

A host of other methods are also offered by the swarm intelligence literature, e.g., bat algorithms (Yang, 2010), differential evolution (Storn \& Price, 1997), artificial immune systems theory (Farmer et al., 1986), glow-worm swarm optimization (Krishnanand \& Ghose, 2005), and others. However, it is beyond the scope of this work to unpack detailed technical aspects of this work; instead the intention is to use these examples as illustrative evidence of the potential contribution of these methods to human swarm solving, or problem solving using human swarms (Rosenberg, 2015).

Rosenberg (2015, p. 658) argues the need for a flexible real-world platform that fosters collective intelligence in "authentic decision-making situations" and offers one allowing groups of online users to make decisions and solve problems by working together in "unified dynamic systems". This echoes theoretical calls for essentially the same type of platform in social innovation coupled with crowdfunding models (Callaghan, 2014b), but which lack a consideration of how to operationalize decision spaces. 
Table 1. Seminal, or 'Source' Swarm Intelligence Methodologies and Application to Human Swarm Solving

\begin{tabular}{|c|c|c|c|}
\hline THEORY & CONTRIBUTION & MECHANISM & $\begin{array}{l}\text { APPLICATION TO HUMAN } \\
\text { SWARM SOLVING }\end{array}$ \\
\hline $\begin{array}{l}\text { Population-based } \\
\text { metaheuristics, and } \\
\text { accelerated } \\
\text { 'memory' develop- } \\
\text { ment (Blum \& Roli, } \\
\text { 2003) }\end{array}$ & $\begin{array}{l}\text { Under disaster or crisis } \\
\text { conditions where data to } \\
\text { manage/solve disaster is } \\
\text { only available after disas- } \\
\text { ter unfolds. }\end{array}$ & $\begin{array}{l}\text { Markov process and } \\
\text { derivation of actions } \\
\text { and next processes }\end{array}$ & $\begin{array}{l}\text { Social media and } \\
\text { crowdsourcing inputs can } \\
\text { provide information maps } \\
\text { of synthesized infor- } \\
\text { mation; and accelerated } \\
\text { 'memory creation' }\end{array}$ \\
\hline $\begin{array}{l}\text { Ant colony optimiza- } \\
\text { tion algorithms (Dor- } \\
\text { igo et al., 2008) }\end{array}$ & $\begin{array}{l}\text { Modeling optimum paths } \\
\text { based on principles de- } \\
\text { rived from the way ants } \\
\text { optimize food-searching } \\
\text { behavior and develop } \\
\text { paths between their colo- } \\
\text { nies and sources of food. }\end{array}$ & $\begin{array}{l}\text { Ants typically lay pher- } \\
\text { omone trails, which } \\
\text { are used by other ants. } \\
\text { Over time these trails } \\
\text { weaken, and other } \\
\text { ants are able to follow } \\
\text { 'stronger' signals, or } \\
\text { paths, thus optimizing } \\
\text { distance to food } \\
\text { sources. Other mecha- } \\
\text { nisms also derive from } \\
\text { this body of work. }\end{array}$ & $\begin{array}{l}\text { Successes of human in- } \\
\text { puts can be modeled as } \\
\text { 'trails', so as streams of } \\
\text { problem-solving expert } \\
\text { crowdsourcing inputs are } \\
\text { differentiated by success- } \\
\text { es, more successful ideas } \\
\text { are able to attract greater } \\
\text { inputs. }\end{array}$ \\
\hline $\begin{array}{l}\text { PSO relates to the } \\
\text { development of algo- } \\
\text { rithms to solve prob- } \\
\text { lems where solutions } \\
\text { represent a point or } \\
\text { a surface in n- } \\
\text { dimensional space } \\
\text { (Kennedy et al., } \\
2001)\end{array}$ & $\begin{array}{l}\text { Modeling interactions of } \\
\text { expert crowdsourcing } \\
\text { collaborators, or disaster } \\
\text { information inputs (for } \\
\text { example), and fitness } \\
\text { properties of their poten- } \\
\text { tial contributions and lo- } \\
\text { cations in relation to other } \\
\text { inputs. }\end{array}$ & $\begin{array}{l}\text { In terms of particle } \\
\text { theory, particles with } \\
\text { initial velocity and } \\
\text { communication and } \\
\text { fitness properties, and } \\
\text { fitness criteria can be } \\
\text { modeled to overcome } \\
\text { local minima con- } \\
\text { straints. }\end{array}$ & $\begin{array}{l}\text { Can offer algorithms to } \\
\text { manage large-scale inputs, } \\
\text { and also problem-solving } \\
\text { inputs in relation to the } \\
\text { problem space, which can } \\
\text { be modeled in different } \\
\text { dimensions. }\end{array}$ \\
\hline $\begin{array}{l}\text { Meta-heuristic artifi- } \\
\text { cial bee colony algo- } \\
\text { rithms (Karaboga, } \\
2005 \text {; Karaboga \& } \\
\text { Akay, 2009) }\end{array}$ & $\begin{array}{l}\text { Differentiates solutions } \\
\text { chosen by deterministic } \\
\text { selection and probabilistic } \\
\text { selection of new opportu- } \\
\text { nities. This model offers } \\
\text { advantages associated } \\
\text { with a balance between } \\
\text { exploration and exploita- } \\
\text { tion, and might usefully be } \\
\text { applied to expert } \\
\text { crowdsourced R\&D. }\end{array}$ & $\begin{array}{l}\text { Modeling the balance } \\
\text { between exploration } \\
\text { and exploitation }\end{array}$ & $\begin{array}{l}\text { Disaster management of } \\
\text { real-time inputs can be } \\
\text { modeled as information } \\
\text { mapping (descriptive in- } \\
\text { formation) and problem } \\
\text { solving (accelerated theo- } \\
\text { ry development) }\end{array}$ \\
\hline
\end{tabular}

Rosenberg's (2015) process, termed 'social swarming', modeled on biological swarms, offers a decision-space which allows participants to converge on preferred solutions in seconds, offering important potential for harnessing collective intelligence. Further, such a process overcomes challenges of asynchronous email-based and discussion forum decision making or polling, which can 
typically introduce herding or snowballing bias effects, and effectively introduces real-time capabilities, as groups of users can answer questions or engage with problem solving "in synchrony" with participants "working as a unified system through real-time feedback loops" (Rosenberg, 2015, p. 658).

Although Rosenberg's (2015) system involves a human swarm collaborating though the use of user-controlled magnets to move a graphical puck, this models a process of collective intelligence, although acknowledged as not conclusive, tests based on models of human swarms also demonstrate that group predictions of football playoffs and Golden Globe and Academy awards were more accurate than the predictions of individuals $(73 \%$ success in predicting winners of 2015 Academy Awards using a dynamic unified system, versus 40\% in written survey, and 55\% for New York Times experts). This evidence suggests swarms can offer a "powerful alternative to the traditional poll-based methods of harnessing the wisdom of crowds", as real-time swarming is a "high-speed process, all decisions made within 60 seconds or less", reflecting improved accuracy of predictions coupled with efficiency (Rosenberg, 2015, p. 659). According to Rosenberg (2015, p. 659):

Why are swarms better than polls? Our analysis suggests that while polls are good at characterising the average views of a population, without real-time feedback control, polls offer no means for groups to explore options and find consensus. Swarms, on the other hand, allow users to continually update their intent in real time, assessing how their views combine with the other participants to achieve an acceptable outcome. In this way, each participant in a swarm is not expressing a singular view, but is continually assessing his own personal conviction across the range of possible options, weighing his confidence and preference in real-time. With all participants doing this in synchrony, the swarm quickly converges on solutions that seem to maximise the collective confidence and preference of the full group. We believe this is why swarms are able [to] efficiently capture the group's wisdom.

Given new technologies that have enabled crowdsourcing and crowdsourced R\&D usages in medical data collection (Adams, 2011; Armstrong, Harskamp, Cheeney, \& Schupp, 2012; Prainsack \& Wolinsky, 2010), interpretation (Foncubierta-Rodriguez \& Müller, 2012; Yu, Willis, Sun, \& Wang, 2013), problem solving (Sims, Bigham, Kautz, \& Halterman, 2014), and medical disaster management (Zook, Graham, Shelton, \& Gorman, 2012), human swarm theory is considered an important addition to the probabilistic innovation literature as it predicts an increasingly important analysis and decision-making role within the crowd itself and, therefore, synthesis of horizontal and vertical (see Figure 1 later in the paper) crowd engagement with real-time problem solving. If the solving of serious societal problems (such as Ebola, Zika, antibiotic resistance, cancer, diabetes, climate change, and chronic aging ailments) in hours or days instead of decades is to ultimately be realized, then the seminal knowledge aggregation problem (Hayek, 1945; Von Hippel, 1994) may require urgent attention, and it is argued probabilistic innovation offers insights toward this end.

The use of the human crowd has extended to paid work in processes that are perhaps analogous to the way swarm intelligence is effective in leveraging inputs of crowds of insects. Theorists such as Kittur et al. (2013) offer theoretical frameworks of crowd work that are "complex, collaborative, and sustainable", based on dimensions of workflow, task assignment, hierarchy, real-time responses, synchronous collaboration, quality control, crowd-directed artificial intelligence, artificial intelligence-guided crowd work, platforms, job design, reputation, and motivation.

The crowd can be used for work with high completion-time constraints; flash crowds can be created, where large groups of individuals can come onto a platform moments after a request to work synchronously on a problem (Kittur et al., 2013). Akin to swarm intelligence in their operation, these processes offer the potential for improvements to research processes and perhaps offer 
theory one bridge further toward the potential of real-time medical research. According to Kittur et al. (2013, n.p.):

The fluid nature of crowd work opens the door to new kinds of hierarchy where workers transition between roles continuously. Crowd management could entail a layered tree made up of worker-leaders, requesters, machine learning systems, and algorithms. In such a setup, participants might be leaf nodes (workers) in one job but managers in another.

Where Kittur et al.'s (2013) notion of 'crowd management' differs here from stigmergy (Garnier et al., 2007), however, is in the notion that the human crowd can also provide an interchangeable 'management', or 'vertical' function as well as a front line, or 'leaf node' worker function (a horizontal function); stigmergy, in contrast, lacks the central coordination of human crowd problemsolving systems. For Kittur et al. (2013, n.p.):

Realizing this vision [of crowd management of 'realtime' crowd work] will require improvements to the platforms (e.g., oDesk teams) and the creation of systems that take advantage of it ... Fast recruitment has been the major research thrust in realtime crowdsourcing so far. Early attempts were motivated by time-limited tasks such as searching for a missing person and timed 'competitions'. In paid crowdsourcing, researchers began emailing a set of workers the night before the study and announced a time for the experiment. Keeping workers busy with old tasks brought wait times down to a half minute to one minute, and paying workers a small wage to stay on call is enough to draw a crowd together roughly two to three seconds later. This technique can be modelled using queuing theory and adapted to bring together crowds in as little as 500 milliseconds.

A core argument of this paper is that, in the same way that the response of insect swarm intelligence is enabled by stigmergy (Garnier et al., 2007), real-time human problem solving by the crowd can also be guided by the unique signals at the interface of the problem. In other words, in the same way as the configuration of an incomplete complex structure offers cues to insect problem solvers to complete it, cues from the unique structure at the point of contact between the individual and the problem structure can enable human problem solvers to 'complete' the problem structure, and solve it. At the unique nexus of the human problem solver (as part of the crowd) and the 'coalface' of the problem, unique cues are available to that individual. The seminal knowledge aggregation problem (Hayek, 1945; Von Hippel, 1994) is essentially solved by populating the structure of the problem at each point of its surface with problem-solving members of the crowd. At this nexus, it is worth posing the question, what underlying problem-solving capacity do crowds potentially have? And, how is this useful in solving management problems across fields, including fields experiencing extreme case problems of time and resource constraints (for example, pandemic disaster management)?

\section{Collective Intelligence of Crowds}

Social insects share collective intelligence-related properties with other forms of biological systems, including, for example, bacteria, schools of fish, flocks of birds, herds of sheep, and crowds of human beings (Garnier et al., 2007). According to Malone, Laubacher, and Dellarocas (2010), Google is an example of how the judgments of millions of people are harnessed as a form of collective intelligence, and so is Wikipedia, which demonstrates the potential of the human crowd for problem solving on a global scale. According to Bonabeau and Théraulaz (2000, p. 47),

Indeed, the potential of swarm intelligence is enormous. It offers an alternative way of designing systems that have traditionally required centralized control and extensive preprogramming. It instead boasts autonomy and self-sufficiency, relying on direct or indirect interactions among simple individual agents. Such operations could lead to systems that can adapt quickly to rapidly fluctuating conditions ... [yet] one criticism of the field is that the 
use of autonomous insectlike agents will lead to unpredictable behavior in the computers they inhabit. This characteristic may actually turn out to be a strength, though, in that it could allow such systems to adapt to solve new, unforeseen problems- a flexibility that traditional software typically lacks.

The emergent properties of problem-solving systems might offer important implications for realtime research. In an attempt to derive common principles that underlie swarm intelligence, Garnier et al. (2007) identify four components that arise at the level of the group out of the interactive behavior of insects, namely, coordination (the organization in space and time of tasks to solve a problem), cooperation (when more than one individual achieve a task that could not be done individually), deliberation (making collective choices between different opportunities), and collaboration (different simultaneous activities performed by specialized individuals). Emergent intelligence, or collective intelligence, is expected to emerge at the level of the collective.

Studies of human problem solving also offer evidence of this 'leverage' effect, or the way collective intelligence contributes to problem solving over and above the influence of individual intelligence. A. W. Woolley et al. (2010, p. 687) found evidence of a general collective intelligence factor, termed the 'c factor', which explains group task performance, defined as "the general ability of the group to perform a wide variety of tasks", a factor analogous to the "general intelligence factor', or ' $\mathrm{g}$ factor' that is a longstanding feature of research on individual intelligence.

The explicit derivation of theory that explains how large-scale problems can be solved in real time rests upon the notion that scale advantages can be enabled, and at the heart of this notion is the need to have large numbers of contributors. The potential of the group to contribute to problem solving in ways that utilize collective intelligence (and which contribute over and above the influence of individual intelligence) offers an assumption that, by logical extension, warrants a consideration of other forms of crowd problem solving, such as swarm intelligence. A more specific perspective of swarm intelligence is now considered.

Garnier et al. (2007) offer more specific examples of how swarm intelligent problem solving is enabled in insect groups, in terms of division of labor (e.g., worker leaf cutter ants belong to different castes which do different work depending on head size), morphogenesis and collective decisions, and how modulation of behavior occurs through small behavior modifications that contribute to the colony's adaptation to environmental conditions. These behaviors happen "as if there was some mysterious virtual agent inside the colony that would coordinate the individuals' activities", despite the absence of any such presence; the "rules that govern interactions between insects are executed on the basis of local information that is without knowledge of the global pattern", using only interaction networks and feedback loops among individuals (Garnier et al., 2007, p. 6). Here there are echoes of the 'invisible hand' logic as well as the 'division of labor' in relation to the work of crowds of social insects.

In relation to the work of human crowds, Malone et al. (2011) extend Adam Smith's (1776/2003) notion of division of labor to a more extreme conception of how knowledge-worker jobs are atomized into complex networks and increasingly specialized sub-components of tasks; in other words, tasks once done by one person are now done by several, typically resulting in dramatic quality, speed and cost improvements. Malone et al. (2011) argue that the open innovation marketplace, through the success of platforms such as InnoCentive, which offer rewards of up to $\$ 100,000$ for successful problem-solving inputs, offer an advantage of hyperspecialization that is denied closed models of innovation in the form of the speed at which research problems can be solved.

Another example of hyperspecialization is a firm called CastingWords that specializes in transcribing audio files by breaking recordings into smaller units and giving these to many transcribers using Amazon's Mechanical Turk site, while also controlling the quality of the work (Malone 
et al., 2011). A powerful implication that arises from this idea of hyperspecialization is that research problems of a previously prohibitively large scale can now be tackled - following Malone et al.'s (2011) logic, the large scale of data itself is no longer necessarily an insurmountable obstacle to problem solving. This notion of hyperspecialization is taken here to be analogous to the way the surface of a problem space may be populated by many different problem solvers, akin to stigmergy, and the way swarm intelligence reflects the mobilization of very large numbers of insects to solve problems like building complex structures. Another analogy to this is the way humans solve pricing problems through the collective intelligence of markets.

\section{From Collective and Swarm Intelligence to the Intelligence of the Crowd in Markets}

Developing theory that relates to the causal structure of collective behavior requires an exploration of the conditions under which these structures manifest themselves. Another example of crowd problem-solving behaviors can be found in markets in general, in the form of the 'invisible hand' hypothesis (A. Smith, 1776/2003) and, more specifically, in the case of financial markets (Surowiecki, 2004). For Fama (1970, p. 383):

The primary role of the stock market is allocation of ownership of the economy's capital stock. In general terms, the ideal is a market in which prices provide accurate signals for resource allocation: that is, a market in which firms can make production-investment decisions, and investors can choose among the securities that represent ownership of firm's activities under the assumption that security prices at any time 'fully reflect' all available information. A market in which prices 'fully reflect' available information is called efficient.

The task of providing these accurate signals for resource allocation is extremely complex, yet the crowd is able to solve this problem reasonably well. In order to provide a concise explanation of the way markets operate, Fama's (1970) seminal explanation is utilized here. According to Fama (1970, p. 387):

First, it is easy to determine sufficient conditions for capital market efficiency. For example, consider a market in which (i) there are no transaction costs in trading securities, (ii) all available information is costlessly available to market participants, and (iii) all agree on the implications of current information for the current price and distributions of future prices of each security. In such a market, the current price of a security obviously 'fully reflects' all available information. But a frictionless market in which all information is freely available and investors agree on its implications is, or course, not descriptive of markets met in practice.

Again, what is important here is the notion that 'sufficient numbers' of investors, or participants, are engaged in the process of solving the price signaling problem. This echoes a core theme of this paper, that the problem space needs to be populated with sufficient numbers of problem solvers, and that an emergent form of problem solving is possible with large numbers of problem solvers, even if at the individual level they are engaged with their own affairs and pursue their own objectives, oftentimes with little thought of others.

There are certain implications that derive from these conceptions. Speculative investments in stock markets should reflect a 'fair game', in that "the expected profits to the speculator should be zero" (Fama, 1970, p. 389), and that stock market prices follow a random walk, whereby "simply the theory of random walks implies that a series of stock market changes has no memory - the past history of the series cannot be used to predict the future in any meaningful way", as the "future path of the price level of a security is no more predictable than the path of a series of random 
numbers" (Fama, 1995, p. 56). What this implies is that the crowd can almost solve the pricing problem in a way that defies the logic of speculators.

The underlying mechanisms of how crowds 'work together' to solve problems seem to share characteristics that have been described as a form of 'spontaneous order'. For Surowiecki (2004, p. 101):

It's safe to say that anyone who's interested in group behavior is enamoured of flocking birds. Of all the hundreds of books published in the past decade on how groups selforganize without direction from above, few have omitted a discussion of bird flocks (or schools of fish). The reason is obvious: a flock is a wonderful example of a social organization that accomplishes its goals and solves problems in a bottom-up fashion, without leaders and without having to follow complex algorithms or complicated rules. Watching a flock move through the air, you get a sense of what the economist Friedrich Hayek liked to term 'spontaneous order.' It's a biologically programmed spontaneity- starlings don't decide to follow these rules, they just do. But it is spontaneity for all that. No plans are made. The flock just moves.

Surowiecki (2004) draws parallels between this spontaneous order and other research that typically shows that with limited knowledge on the part of individuals, efficient markets 'form' spontaneously in a way analogous with the 'invisible hand' predictions of A. Smith (1776/2003). The importance of this body of research, according to Surowiecki (2004), is that it shows (i) that the emergent properties of the system do not require complete information on the part of individuals, but only limited information, and (ii) that a socially valuable outcome (a market that tends to maximize the benefit to all involved) is obtained when individuals act out of self-interest, or are simply motivated to maximize their own utility.

Notwithstanding the imperfections of markets under certain conditions, Surowiecki (2004, p. 107) stresses that this body of research strongly supports the notion that individuals without complete knowledge can "coordinate themselves to achieve complex, mutually beneficial ends even if they're not really sure, at the start, what those ends are or what it will take to accomplish them". For V. Smith (1962, p. 134), on the basis of his experiment on emergent market formation:

The so-called Walrasian hypothesis concerning the mechanism of market adjustment seems not to be confirmed. A more adequate hypothesis is the excess-rent hypothesis which relates the 'speed' of contract price adjustment to the algebraic excess of buyer plus seller 'virtual' rent over the equilibrium buyer plus seller rent. This new hypothesis becomes particularly intriguing in view of the fact that a competitive market for a single commodity can be interpreted as seeking to maximize total rent.

V. Smith's (1962) seminal contribution here appears to hinge on the finding that the emergent solutions seem to maximize benefit in total, notwithstanding the fact that individuals are acting out of self-interest. Instead of the Walrasian notion that adjustment mechanisms are perfect and automatic, V. Smith (1962) argues that large numbers of problem solvers act together in the interests of the collective. It is also proposed in this paper that this effect can extend to a 'market' for the solutions of problems and, more specifically, to the way an open exchange of ideas and problem-solving inputs can solve difficult but knowable problems, such as curing diseases or problems associated with aging. It is therefore suggested here that the use of crowdsourcing as a form of R\&D may offer an opportunity for scientific research to harness such 'emergent properties' that arise in a way similar to how the behaviors of individuals converge to solve problems in these other settings.

In the sections above, a range of different theories were introduced and discussed. It was suggested that this body of theory has important implications for the arguments made in this paper. Im- 
portantly, the way inputs from large numbers of people seem to be able to solve the knowledge aggregation problem (Hayek, 1945; Von Hippel, 1994) offers certain insights into how 'scalable' problem solving might be enabled, or economies of scale can exist when the crowd is tasked with problem solving. A core contention of this paper is that, analogous to certain of the theoretical perspectives considered above, in certain circumstances, the probability of solving a problem can be maximized under conditions that approximate a 'market' of ideas, or a tradable market consisting of 'intrinsic' payoffs, or the satisfaction/utility that individuals receive for making knowledge contributions as well as extrinsic payoffs such as remuneration or awards.

Similarly, the emergence of information technology in the form of the internet might have enabled unprecedented access to the crowd, and the latent power of the crowd to solve problems is only now beginning to be recognized. However, practical lessons from crowdsourcing, where work is increasingly efficiently performed by the crowd, perhaps point the way to how collective problem solving might be operationalized. Hyperspecialization is an emerging area of theory with important implications for the practical aspects of crowdsourced problem solving. Figure 1 shows a conceptual model which uses certain principles derived from hyperspecialization to illustrate the way a problem landscape surface might be populated by large numbers of problem solvers. It is possible that such a structure might enable the collective intelligence of the crowd to shape engagements with the problem space.

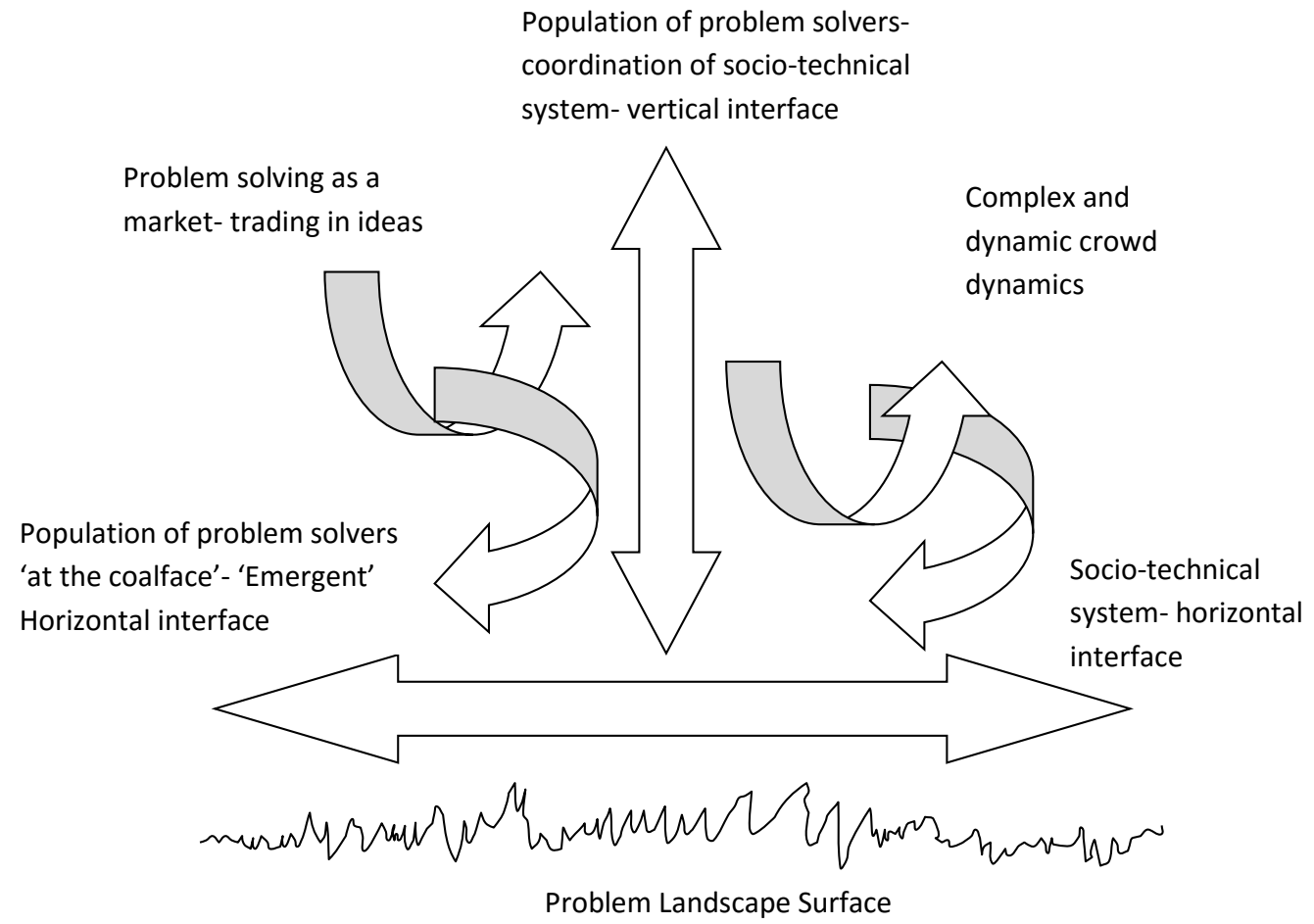

Figure 1: Crowdsourced R\&D and Real-time Swarm Solving

To incentivize large-scale inputs, hyperspecialization uses novel incentivization schemes, ranging from monetary payments to forms of recognition and autonomy-related payoffs for contributors to choose the nature of their contribution to crowdsourced contributions (Malone et al., 2011). An 
important implication of the emergence of hyperspecialization is a shift in the way workers are perceived; attracting talented communities of workers may become an increasingly important aspect of organizational management (Malone et al., 2011). However, as with all forms of crowd problem solving, quality control is vital.

The integration of inputs is, however, also a challenge associated with hyperspecialization, requiring certain dimensions of dependency to be monitored and managed, namely, flow (routing work), sharing (when multiple workers share the same resource, typically resolved by some form of markets and bidding), and fit (when outputs need to be integrated to fit together); however, solving challenges associated with dimensions of dependency can in turn be allocated to members of the crowd, termed 'copilots', who essentially hyperspecialize in coordinating these inputs (Malone et al., 2011).

Illustrating certain of the ideas considered previously, the horizontal arrow in Figure 1 represents a process of human problem solving akin to stigmergy, or the way swarm intelligence allows a complex problem space (for instance, solving complex architectural problems such as building complex structures) to be populated with insect problem solvers as a form of hyperspecialization. In the case of real-time crowdsourced $R \& D$, this hyperspecialized horizontal engagement with the problem, however, is also coordinated by a vertical interface of 'copilots' following Malone et al.'s (2011) conceptualization, which combines the effect of sigmergy with the advantages of centralized information organization and coordination. In this way, both swarm intelligence mechanisms and collective intelligence mechanisms provide synergistic outcomes to push the system of problem solving toward real-time outcomes. The discussions of the literature above are taken to relate to the enabling conditions of real-time human swarm solving.

It is hoped that these initial conceptions can be further developed to support the nascent field of probabilistic innovation. If the collective intelligence of crowds, expert or not, could be more effectively harnessed in support of management problem solving, this could make an important contribution, particularly to fields that experience high costs related to the lack of real-time problem-solving capabilities.

\section{Theoretical, Methodological, and Practical Implications}

Table 2 summarizes theoretical, methodological, and practical implications of the swarm solving process derived from probabilistic innovation theory. Whereas probabilistic innovation theory seeks to develop knowledge of linkages and mechanisms supporting real-time research capability, swarm solving represents a method of accelerating research productivity. Theoretical implications that derive from this analysis include the following. First, applying the extreme case method of swarm solving as a heuristic to facilitate analysis of maximized collaboration enables causal channels of constraints to research processes to be identified. Second, such analysis strengthens theoretical frameworks relating to real-time research productivity, through the identification of boundary conditions to theoretical predictions around the attainment of real-time research capability. Third, extreme scenarios of swarm solving push theory development to take conditions into account where time is maximally constrained and maximum congestion cannot be avoided.

Fourth, probabilistic innovation theory imposes a constraint on theory development; in the same way as mathematical equations are constrained, theory constrained to have to consider maximum time constraints can ultimately provide a 'stony ground' context in which only effective innovative ideas and theory can 'grow' with the goal of attaining robust theory to guide research into real-time research productivity.

As part of the probabilistic innovation epistemology, swarm solving represents a methodology, which (i) is based on large-scale knowledge management, including crowdsourcing, which is well established in scientific fields; (ii) seeks to maximize information collection and collaboration; 
(iii) is related methodologically to citizen science, participant-led research and other movements associated with the democratization of science; and (iv) relates to scientific movements advocating transparency in science.

\section{Table 2. Theoretical, Methodological and Practical Implications of Swarm Solving and Probabilistic Innovation Theory}

\section{THEORETICAL IMPLICATIONS}

Heuristic of maximized collaboration enables causal channels of constraints to research processes to be identified. Theoretical framework relating to real-time research productivity strengthened through the identification of boundary conditions.

Extreme scenarios of swarm solving push theory development to take conditions into account where time is maximally constrained.

Probabilistic innovation theory imposes a constraint on theory development; under time constraints innovative ideas are necessary.

\section{METHODOLOGICAL IMPLICATIONS}

Probabilistic innovation theory taken to offer a methodology based on large-scale knowledge management, including crowdsourcing.

These methods are based on maximized information collection and collaboration, with the extreme case being swarm solving.

Methodologically related to citizen science, participant-led research and democratization of science, as well as maximized transparency.

Methodological proof of concept of crowdsourced R\&D is extended using maximization heuristics.

\section{PRACTICAL IMPLICATIONS}

The use of maximized heuristics offers useful insights for those seeking to increase the effectiveness and efficiency of research processes.

Derived principles can be useful for reducing the time dimension of research projects.

Insights can be helpful in managing congestion in research projects that involve large numbers of collaborators. Helps with understanding the challenges related to collaboration in research.

The use of swarm solving as an extreme case heuristic arguably offers useful insights for those seeking to increase the effectiveness and efficiency of research processes. Derived principles can be useful to reduce the time dimension of research projects, while insights can be helpful in managing congestion in research projects with large numbers of collaborators. The analysis can also help understandings of challenges related to collaboration in research.

As a summary, Figure 2 provides an overview of the literature and theory considered in this paper. Failure of academic research over time to provide innovations at a sufficient rate (Dewald, Thursby, \& Anderson, 1986) and the failure of markets to deliver much needed innovation in socially important areas (Martin \& Scott, 2000), particularly in pharmaceutical research (Horrobin, 2010), despite exponential growth in information and knowledge (Adair \& Vohra, 2003) are arguably long-standing challenges in the absence of real-time research capabilities. It was argued that the knowledge aggregation problem (Hayek, 1945; Von Hippel, 1994), or stickiness of knowledge, is the theoretical problem at the heart of problems in bringing knowledge together effectively in real time. 


\section{THE CHALLENGE}

FAILURE OF ACADEMIC RESEARCH TO PROVIDE INNOVATIONS

Dewald, Thursby and Anderson (1986)

MARKET INNOVATION FAILURE

Martin and Scott (2000)

PHARMACEUTICAL INNOVATION FAILURE

Horrobin (2010)

EXPONENTIAL GROWTH IN INFORMATION AND KNOWLEDGE

Adair and Vohra (2003)

KNOWLEDGE AGGREGATION PROBLEM

Hayek (1945); Von Hippel (1994)

\section{SWARM SOLVING LITERATURE}

SELF-ORGANISING COOPERATION OF

SWARMS

Bonabeau and Théraulaz (2000)

Garnier et al. (2007)

CROWD WORKFLOW COLLABORATION

Kittur et al. (2013); Malone et al. (2011)

COLLECTIVE INTELLIGENCE

Malone and Klein (2007); A. W. Woolley et al. (2010)

INTELLIGENCE' OF CROWD MARKET

MECHANISMS

Fama (1970); A. Smith (1776/2003); V. Smith

(1962)

TIME EFFECTIVE RESEARCH PROCESSES

Probabilistic innovation theory (Callaghan, 2015)

\section{ENABLING CONDITIONS}

EXPONENTIAL GROWTH IN INFORMATION AND KNOWLEDGE

Adair and Vohra (2003)

CROWDSOURCED R\&D PROOF OF CON-

CEPT

Howe (2006)

GOOGLE, WIKIPEDIA AND OTHER CASE STUDIES

Malone et al. (2010)

Figure 2. Swarm Solving Theoretical Literature

It was argued that useful principles can be derived from the study of social insects, particularly in terms of self-organizing properties (Bonabeau \& Théraulaz; 2000; Garnier et al., 2007), which, linked to rapidly developing theory and literature on crowd work and its mechanisms of workflow which maximize the effectiveness of collaborations (Kittur et al., 2013; Malone et al., 2011), may offer important insights for theory that seeks to develop real-time research capabilities. Evidence of collective intelligence (Malone \& Klein, 2007; A. W. Woolley et al., 2010) that results from collaborations was related to mechanisms through which crowds, or large numbers of people, solve pricing problems in financial markets (Fama, 1970), or resource problems in general (A. Smith, 1776/2003) was also considered for insights derived for real-time research problem solving. Instructional designers and training managers might usefully incorporate these principles and lessons and proactively aid the dissemination of this knowledge in fields facing the need for realtime research problem solving, as these principles might generalize to contexts which share the need for large-volume data collection, synthesis and analysis in real time. For example, according to Alexander $(2014$, p. 717$)$, the widespread adoption and use of social media by populations "heralds a new age" for disaster management and emergency managers, who need to "adapt their working practices to the challenge and potential of this development". Similarly, the emergence of social media and crowdsourcing technologies requires theoretical frameworks to draw litera- 
ture streams together, providing an explicit focus on real-time disaster management or crisis problem solving (Callaghan, 2016). The contribution of this research is, therefore, to apply swarm and collective intelligence theory to human, rather than to artificial, intelligence systems of realtime problem solving. The overarching objective of this paper was, therefore, to derive principles useful to those seeking to improve the effectiveness and efficiency of research processes across fields by analyzing the extreme case of swarm solving, or solving problems in real time, using very large numbers of problem-solving inputs.

\section{Limitations}

As with all conceptual research, this paper is not free of limitations. Certain limitations ascribed to conceptual theory development in social sciences are now considered. Inherent to theory development is the need to develop testable theory, and the paper has sought to do this. It is acknowledged, however, that this research itself suffers certain limitations associated with fundamental constraints to innovation (Kuhn, 1970; Lakatos, 1970), as well as those associated with its location within the functionalist or realist paradigm (Burrell \& Morgan, 1979) and its quest to pursue modernist or enlightenment ideas. However, dystopian outcomes are not taken to be necessary outcomes of the scientific advances (Latour, 2000) proposed here, because probabilistic innovation methodologies are premised on ethical population or crowd verification of scientific processes (Funtowicz \& Ravetz, 1994), as well as the maximized collaborative engagement of citizen science crowds with scientific problem solving (Bonney et al., 2009; Garbarino \& Mason, 2016), associated with the 'democratization' of science. Methodologically, the conceptual approach of this paper sought to follow principles of validity (Campbell \& Fiske, 1959) by offering multiple and different perspectives to support arguments. It is hoped further research will test theory presented in this work, as further theory development in this area will only be strengthened through rigorous reflexivity and empirical tests of its developing tenets.

\section{Conclusion and Recommendations for Further Research}

The primary objectives of this research were to derive theoretical, methodological, and practical implications from swarm intelligence theory and to derive a model of real-time research problem solving based on a synthesis of literature. In attempting to understand the way the management of knowledge can contribute to the radical acceleration of innovation (and how a radical improvement in the quest to achieve real-time research could be achieved), with a focus on swarm intelligence, this paper presented a host of theoretical frameworks, including those relating to collective intelligence, the theory of markets, and how the use of the crowd can contribute to problem solving. An extreme case heuristic was used, namely swarm solving, which draws on swarm intelligence theory to derive a model of how real-time problem solving can occur when collaborations are maximized. Theory and practice were considered that relate to how the crowd can be harnessed in a more practical way, in order to support the practicality of these conceptualizations. Two primary concepts were derived from the literature. The first relates to how swarm intelligence is typically operationalized by stigmergy, or how problem spaces are 'eroded' by individuals who obtain information (and cues for problem solving) about the unique configuration of the problem at their specific nexus with the problem space. The second concept relates to how the horizontal process of stigmergy or hyperspecialization based on human crowds (unlike in the case of swarm intelligence) can also rely on the crowd to provide vertical coordination. Theoretical, methodological and practical implications relating to analyses were derived.

In short, theoretical concepts were used to support an argument that certain of the principles synthesized from this body of theory can be applied to the way problems are solved using the crowd, or crowdsourced R\&D, and that while the goal of real-time research might not be fully attainable yet, certain strides towards this end can be made by building on these conceptions. Future re- 
search is suggested to empirically test conceptions developed here and to develop 'micro-level' theory around ways to operationalize these principles in practice. Such theory might usefully build on further swarm intelligence principles to support those in practice attain real-time research capability. Although (currently) seemingly unattainable, it is possible theory development around real-time problem solving might eventually contribute to a world in which serious societal problems can be solved in hours or days instead of decades or centuries.

\section{References}

Alexander, D. E. (2014). Social media in disaster risk reduction and crisis management. Science and Engineering Ethics, 20(3), 717-733.

Adair, J. G., \& Vohra, N. (2003). The explosion of knowledge, references, and citations: Psychology's unique response to a crisis. American Psychologist, 58, 15-23.

Adams, S. A. (2011). Sourcing the crowd for health services improvement: The reflexive patient and 'share your experience' websites. Social Science \& Medicine, 72(7), 1069-1076.

Ajumobi, K. (2014). War against polio: Nigeria reports single case in 2014. Retrieved September 15, 2014, from http://businessdayonline.com/2014/04/war-against-polio-nigeria-reports-single-case-in$\underline{2014 /}$

Allio, R. (2004). CEO interview: The InnoCentive model of open innovation. Strategy \& Leadership, $32(4), 4-9$.

Armstrong, A. W., Harskamp, C. T., Cheeney, S., \& Schupp, C. W. (2012). Crowdsourcing for research data collection in rosacea. Dermatology Online Journal, 18, 3.

Aye, Z. C., Sprague, T., Cortes, V. J., Prenger-Berninghoff, K., Jaboyedoff, M., \& Derron, M.-H. (2016). A collaborative (web-GIS) framework based on empirical data collected from three case studies in Europe for risk management of hydro-meteorological hazards. International Journal of Disaster Risk Reduction, 15, 10-23.

Bianchi, L., Dorigo, M., Gambardella, L. M., \& Gutjahr, W. J. (2009). A survey on metaheuristics for stochastic combinatorial optimization. Natural Computing: An International Journal, 8(2), 239-287.

Blum, C., \& Roli, A. (2003). Metaheuristics in combinatorial optimization: Overview and conceptual comparison. ACM Computing Surveys, 35(3), 268-308.

Bonabeau, E., \& Theraulaz, G. (2000). Swarm smarts. Scientific American, 282(3), 72-79.

Bonney, R., Cooper, C. B., Dickinson, J., Kelling, S., Phillips, T., Rosenberg, K. V., \& Shirk, J. (2009). Citizen science: A developing tool for expanding science knowledge and scientific literacy. BioScience, 59(11), 977-984.

Burrell, G., \& Morgan, G. (1979). Sociological paradigms and organisational analysis. London: Heinemann.

Callaghan, C. W. (2014a). Solving Ebola, HIV, antibiotic resistance and other challenges: The new paradigm of probabilistic innovation. American Journal of Health Sciences, 5(2), 165-178.

Callaghan, C. W. (2014b). Crowdfunding to generate crowdsourced R\&D: The alternative paradigm of societal problem solving offered by second generation innovation and R\&D. The International Business \& Economics Research Journal, 13(6), 1499-1513.

Callaghan, C. W. (2015). Crowdsourced 'R\&D' and medical research. British Medical Bulletin, 115, 1-10.

Callaghan, C. W. (2016). Disaster management, crowdsourced R\&D and probabilistic innovation theory: Toward real time disaster response capability. International Journal of Disaster Risk Reduction. doi: 10.1016/j.ijdrr.2016.05.004

Campbell, D. T., \& Fiske, D. W. (1959). Convergent and discriminant validation by the multitraitmultimethod matrix. Psychological Bulletin, 56, 81-105. 
Chan, C., \& Holosko, M. J. (2015). An overview of the use of Mechanical Turk in behavioral sciences: Implications for social work. Research on Social Work Practice, 1-8.

Coetzee, C., Van Niekerk, D., \& Raju, E. (2016). Disaster resilience and complex adaptive systems theory: Finding common grounds for risk reduction. Disaster Prevention and Management, 25(2), 196-211.

Davies, N. (2015). Disaster response gets boost from AI, crowdsourced data. Retrieved March 14, 2016 from http://www.extremetech.com/extreme/208180-crowd-sourcing-data-for-humanitarian-disasterresponse

De Falco, S. E., Vargas-Sánchez, A., \& Cucari, N. (2015). Social Innovation practices: Focus on success factors for crowdfunding. Retrieved February 25, 2016 from www.naplesforumonservice.it/uploads/files/EspositoDeFalco

Dewald, W. G., Thursby, J. G., \& Anderson, R. G. (1986). Replication in empirical economics: The Journal of Money, Credit and Banking Project. The American Economic Review, 76(4), 587-603.

Dorigo, M. (1993). Genetic and non-genetic operators in ALECSYS. Evolutionary Computation, 1(2), 151-164.

Dorigo, M., Birattari, M., Blum, C., Clerc, M., Stützle, T., \& Winfield, A. (Eds). (2008). Ant colony optimization and swarm intelligence. Proceedings of the 6th International Conference, ANTS 2008, Brussels, Belgium, September 22-24. (Vol. 5217). Springer.

Dorigo, M., \& Gambardella, L. M. (1997). Ant colony system: A cooperative learning approach to the traveling salesman problem. Evolutionary Computation, IEEE Transactions on, 1(1), 53-66.

Dorigo, M., Maniezzo, V., \& Colorni, A. (1996). Ant system: Optimization by a colony of cooperating agents. Systems, Man, and Cybernetics, Part B: Cybernetics, IEEE Transactions on, 26(1), 29-41.

Fama, E. (1970). Efficient capital markets: A review of theory and empirical work. The Journal of Finance, $25(2), 383-417$.

Fama, E. (1995). Random walks in stock market prices. Financial Analysis Journal, 76, 75-80.

Farmer, J. D., Packard, N. H., \& Perelson, A. S. (1986). The immune system, adaptation, and machine learning. Physica D, 2(1-3), 187-204.

FDA. (2015). What are "biologics": Questions and answers. U.S. Food and Drug Administration. Retrieved November 3, 2014, from http://www.fda.gov/AboutFDA/CentersOffices/OfficeofMedicalProductsandTobacco/CBER/ucm1330 77.htm

Foncubierta-Rodriguez, A., \& Müller, H. (2012). Ground truth generation in medical imaging: A crowdsourcing-based iterative approach. In Proceedings of the ACM multimedia 2012 workshop on Crowdsourcing for multimedia, 9-14.

Forrest, S. (1990). Emergent computation: Self-organizing, collective, and cooperative phenomena in natural and artificial computing networks. Physica D, 42, 1-11.

Funtowicz, S. O., \& Ravetz, J. R. (1994). Uncertainty, complexity and post-normal science. Environmental Toxicity and Chemistry, 13(12), 1881-1885.

Garbarino, J., \& Mason, C. E. (2016). The power of engaging citizen scientists for scientific progress. Journal of Microbiology \& Biology Education, March, 7-12.

Garnier, S., Gautrais, J., \& Theraulaz, G. (2007). The biological principles of swarm intelligence. Swarm Intelligence, 1, 3-31.

Grasela, T. H., \& Slusser, R. (2014). The paradox of scientific excellence and the search for productivity in pharmaceutical research and development. Clinical Pharmacology \& Therapeutics, 95(5), 521-527.

Halifax, J. (2013). Superbugs immune to antibiotics a threat to humans as big as terrorism or climate change. Retrieved July 17, 2014, from http://www.birminghammail.co.uk/lifestyle/health/superbugsimmune-antibiotics-bigger-threat-3410907 
Hayden, E. C. (2014). Technology: The \$1,000 genome. Nature, 507, 294-295.

Hayden, F. (2006). Antiviral resistance in influenza viruses: Implications for management and pandemic response. The New England Journal of Medicine, 354(8), 785-788.

Hayek, F. A. (1945). The use of knowledge in society. The American Economic Review, 35(4), 519-530.

Horrobin, D. F. (2000). Innovation in the pharmaceutical industry. Journal of the Royal Society of Medicine, 93, 341-345.

Howe, J. (2006). The rise of crowdsourcing. Wired Magazine, 14.06. Retrieved 12 June, 2013, from http://sistemas-humano-computacionais.wdfiles.com/local--files/capitulo\%3Aredessociais/Howe The Rise of Crowdsourcing.pdf

Johnson, N. L. (1998). Collective problem solving. Los Alamos National Laboratory. Working Paper LAUR-98-2227. Retrieved October 2, 2014, from http://collectivescience.com/Documents_1/Johnson $\% 20$ Collective $\% 20$ Problem $\% 20$ Solving $\% 20 \mathrm{AB} \% 2$ Opaper\%20v11f\%201998.pdf

Karaboga, D. (2005). An idea based on honey been warm for numerical optimization. Technical Report TR06, Erciyes University, Engineering Faculty, Computer Engineering Department.

Karaboga, D., \& Akay, B. (2009). A comparative study of artificial bee colony algorithm. Applied Mathematics and Computation, 214, 108-132.

Kennedy, J. (1999). Minds and cultures: Particle swarm implications for beings in sociocognitive space. Adaptive Behavior, 7(3/4), 269-288.

Kennedy, J., Eberhart, R. C., \& Shi, Y. (2001). Swarm intelligence. Morgan Kaufmann: Academic Press.

Kittur, A., Nickerson, J. V., Bernstein, M. S., Gerber, E. M., Shaw, A., Zimmerman, J., ... Horton, J. J. (2013). The future of crowd work. Proceedings of the 2013 conference of Computer supported cooperative work, 1301-1318.

Kochugovindan, S., \& Vriend, N. J. (1998). Is the study of complex adaptive systems going to solve the mystery of Adam Smith's 'invisible hand'? The Independent Review, 3(1), 53-66.

Krishnan, J. (2014). Panic as deadly Ebola virus spreads across West Africa. Retrieved February 25, 2015, from http://www.independent.co.uk/news/world/africa/panic-as-deadly-ebola-virus-spreads-acrosswest-africa-9241155.html

Krishnanand, N. K., \& Ghose, D. 2005. Detection of multiple source locations using a glowworm metaphor with applications to collective robotics. Swarm Intelligence Symposium. Proceedings IEEE, 84 91.

Kuhn, T. S. 1970. The structure of scientific revolutions (2nd ed.). Chicago: University of Chicago Press.

Lakatos, I. (1970). Falsification and the methodology of scientific research programmes. In I. Lakatos \& A. Musgrave (Eds), Criticism and the growth of knowledge. Cambridge: Cambridge University Press. Retrieved May 1, 2016, from www.csun.edu/ vcsoc00i/classes/s497f09/s690s08/Lakatos.pdf

Latour, B. (2000). When things strike back: A possible contribution of 'science studies' to the social sciences. British Journal of Sociology, 51(1), 107-123.

Ling, L. L., Schneider, T., Peoples, A. J., Spoering, A. L., Engel, I., Conlon, B. P., ... Lewis, K. (2015). A new antibiotic kills pathogens without detectable resistance, Nature. doi: 10.1038/nature14098

Malone, T. W., \& Klein, M. (2007). Harnessing collective intelligence to address global change, Innovations, 2(3), 15-26.

Malone, T. W., Laubacher, R., \& Dellarocas, C. (2010). The collective intelligence genome. Sloan Management Review, 5(3), 21-31.

Malone, T. W., Laubacher, R., \& Johns, T. (2011). The big idea: The age of hyperspecialization. Harvard Business Review, 89(7/8), 56-65. 
Martin, S., \& Scott, J. T. (2000). The nature of innovation market failure and the design of public support for private innovation. Research Policy, 29, 437-447.

McKenna, M. (2014). Sneak peek: What the White House is thinking about antibiotic resistance. Retrieved March 12, 2015, from http://www.wired.com/2014/04/pcast-resistance/

Munos, B. (2009). Lessons from 60 years of pharmaceutical innovation. Nature Reviews Drug Discovery, 8, 959-968.

Nielsen, K. R., Reisch, L., \& Thøgersen, J. (2014). Users, innovation and sustainability. Retrieved February 25,2016 , from file:///C:/Users/a0010874/Downloads/EU.Innovate\%20Deliverable\%206.1.\%20Users\%20Innovation\% 20and\%20Sustainability.pdf

Northeastern University. (2015). Newly discovered antibiotic kills pathogens without resistance. Science Daily. Retrieved June 2, 2015, from www.sciencedaily.com/releases/2015/01/150108124854.htm

Pierson, R., \& Berkrot, B. (2016). U.S. sees first case of bacteria resistant to last-resort antibiotic. Retrieved May 28, 2016, from http://www.reuters.com/article/us-health-superbug-idUSKCNOYH2KT

Prainsack, B., \& Wolinsky, H. (2010). Direct-to-consumer genome testing: Opportunities for pharmacogenomics research? Pharmacogenomics, 11(5), 651-655.

Rosenberg, L. B. (2015). Human swarms: A real-time method for collective intelligence. Proceedings of the European Conference on Artificial Life, 658-659.

Senthilingam, M. (2015). Are we ready for the next global epidemic? CNN. Retrieved June 29, 2015, from http://edition.cnn.com/2015/02/13/health/are-we-ready-for-global-outbreak/

Sims, M. H., Bigham, J., Kautz, H., \& Halterman, M. W. (2014). Crowdsourcing medical expertise in near real time. Journal of Hospital Medicine, 9(7), 451-456.

Smith, A. (2003). The wealth of nations. New York: Bantam Dell. (Original work published 1776)

Smith, V. (1962). An experimental study of competitive market behavior. The Journal of Political Economy, 70(2), 111-137.

Steuli, J. C., \& Vayena, E. (2016). The promising revolution of participant-led research in rare neurological diseases; Potential benefits and pitfalls. Epileptologie, 32, 177-182.

Storn, R., \& Price, K. (1997). Differential evolution: A simple and efficient heuristic for global optimization over continuous spaces. Journal of Global Optimization, 11, 341-359.

Surowiecki, J. (2004). The wisdom of crowds. London: Little, Brown.

Tierney, T. F. (2014) Crowd-sourcing disaster response: Mobilising social media for urban resilience. The European Business Review. Retrieved August 17, 2015, from http://www.europeanbusinessreview.com/?p=4911

Torr-Brown, S. (2013). Crowdsourcing for science and medicine: Progress and challenges. The Journal of Onco Pathology, 1(2), 75-81.

Vayena, E., \& Tasioulas, J. (2013). The ethics of participant-led biomedical research. Nature Biotechnology, 31(9), 786-787.

Von Hippel, E. (1994). 'Sticky information' and the locus of problem solving: Implications for innovation. Management Science, 40(4), 429-439.

Woolley, A. W., Chabris, C. F., Pentland, A., Hashmi, N., \& Malone, T. W. (2010). Evidence for a collective intelligence factor in the performance of human groups. Science, 330(6004), 686-688.

Woolley, J., Madsen, T. L., \& Sarangee, K. (2015). Crowd-sourcing or expertsourcing: Building and engaging online communities for innovation? Conference Paper Presented at DRUID15, June 15-17, Rome. Retrieved August 12, 2015, from http://druid8.sit.aau.dk/acc papers/qmhancfmt4ueanyebhgvngixddcu.pdf 
Yang, X. S. (2010). A new metaheuristic bat-inspired algorithm. In C. Cruz, J. R. González, N. Krasnogorm, D. A Pelta, \& G. Terrazas (Eds), Nature inspired cooperative strategies for optimization (NISCO 2010). Retrieved May 27, 2016, from http://arxiv.org/abs/1004.4170

Yates, D., \& Paquette, S. (2011). Emergency knowledge management and social media technologies: A case study of the 2010 Haitian earthquake. International Journal of Information Management, 31, 613.

Yesodha, R., \& Amudha, T. (2012). A comparative study on heuristic procedures to solve bin packing problems. International Journal in Foundations of Computer Science \& Technology, 2(6), 37-49.

Yu, B., Willis, M., Sun, P., \& Wang, J. (2013). Crowdsourcing participatory evaluation of medical pictograms using Amazon Mechanical Turk. Journal of Medical Internet Research, 15(6), e108.

Zia, A. (2014). Newly diagnosed child brings polio cases to 40. Retrieved December 10, 2014, from http://tribune.com.pk/story/691219/newly-diagnosed-child-brings-polio-cases-to-40/

Zook, M., Graham, M., Shelton, T., \& Gorman, S. (2012). Volunteered geographic information and crowdsourcing disaster relief: A case study of the Haitian earthquake. World Medical and Health Poli$c y, 29(2), 7-33$.

\section{Biography}

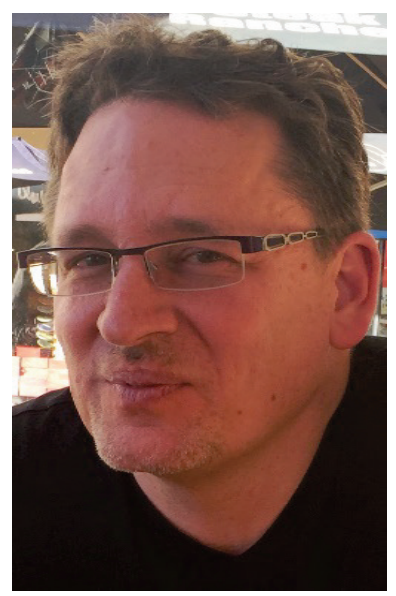

Chris William Callaghan is an Associate Professor in the School of Economic and Business Sciences of the University of the Witwatersrand, in Johannesburg, South Africa. His is founder and Director of the Knowledge and Information Economics/Human Resources Research Agency (KIEHRA). A key stream of his research relates to how information and knowledge can be better used to solve serious societal problems. Key to this is developing theory around how connectivity and collaborations between researchers can be maximized to enable accelerated problem solving, and to harness human collective intelligence in support of socially important innovation. 